\title{
ALGUMAS DIFERENÇAS COMUNICATIVAS ENTRE O PORTUGUÊS E O INGLÊS
}

Cristiane Roscoe-Bessa*

Universidade de Brasília

Márcia Ney Pessoa**

Universidade de Brasília

\author{
Izabel Cristina Brum Dias**** \\ Universidade de Brasília
}

\begin{abstract}
Resumo: Este estudo tem como objetivo analisar diferenças ou similaridades comunicativas entre o inglês e o português, a partir do pressuposto de que tal conhecimento pode ser útil na atividade do tradutor em sua tentativa de melhor traduzir os fenômenos discursivos. Acreditamos que a conscientização de diferenças comunicativas dentro de um par linguístico pode evitar inconsistências de discurso e até mesmo desentendimentos entre falantes de línguas distintas. Constatamos que a literatura enfati-
\end{abstract}

* Cristiane Roscoe-Bessa: Doutora (2006) em Linguística pela Universidade de São Paulo (USP). Mestre (2000) em Linguística Aplicada e Bacharel (1988) em Tradução-Inglês pela Universidade de Brasília (UnB). Professora do Departamento de Línguas Estrangeiras e Tradução da Universidade de Brasília. Brasília, Distrito Federal, Brasil. E-mail: crbessa@unb.br

** Márcia Ney Pessoa: Mestranda em Estudos de Tradução pela Universidade de Brasília (UnB). Graduada (1988) em Letras. Brasília, Distrito Federal, Brasil. E-mail: marcianey@gmail.com

*** Izabel Cristina Brum Dias: Mestranda em Estudos de Tradução pela Universidade de Brasília (UnB). Graduada (2007) em Letras pela Faculdade Porto Alegrense. Brasília, Distrito Federal, Brasil. E-mail: izabelb.dias@gmail.com 
za as diferenças estruturais entre o inglês e o português, porém não as diferenças discursivas. Por isso, propomos uma identificação preliminar dessas diferenças a partir das pesquisas de House (1997), Le Berre (2008), Negrão (2001), Piccolo (2002) e Nogueira (2013) com quem dialogamos para fundamentar nosso trabalho.

Palavras-chave: Diferenças Comunicativas. Inglês e Português. Tradução.

\title{
SOME COMMUNICATIVE DIFFERENCES BETWEEN PORTUGUESE AND ENGLISH
}

\begin{abstract}
This paper tackles communicative differences or similarities between English and Portuguese, from the assumption that this knowledge may be useful in the translator's activity in attempting to translate better discursive phenomena. We believe that the awareness of communicative differences within a language pair can avoid discourse inconsistencies and even misunderstandings between speakers of different languages. We found that the literature emphasizes the structural differences between English and Portuguese, but not the discursive differences. Therefore, we propose a preliminary identification of these differences from the research of House (1997), Le Berre (2008), Negrão (2001), Piccolo (2002) and Nogueira (2013) with whom we dialogue to support our study.

Keywords: Communicative Differences. English and Portuguese. Translation.
\end{abstract}

Apontamos neste estudo alguns contrastes e semelhanças que existem entre as escolhas comunicativas do par linguístico inglês -português, especialmente no contexto do discurso brasileiro. Diferenças pragmáticas representam um dos pontos mais sutis do processo tradutório e têm fundamental importância para um bom resultado final. Para maior fluidez, requisito essencial da tradução de textos em contextos especializados, é necessário que se observem cuidadosamente essas diferenças. No entanto, enfrentamos dificuldade para encontrar dados que, de fato, se referissem às diferenças pragmático-discursivas entre o inglês e o português e, até mesmo, às características comunicativas do discurso em português. Por isso, a partir de uma breve análise bibliográfica e da pesquisa empírica, apresentamos algumas dessas diferenças. 
Nosso ponto de partida foram as análises contrastivas pragmáticas referidas por House (1997), em seu modelo revisitado, e na comparação do discurso de falantes nativos do alemão e do inglês conduzida por ela na Universidade de Hamburgo a partir dos anos de 1970 e 1980 . House (1997, p. 80) salienta que sua investigação se fundamentou "no modelo de análise discursiva apresentado por Edmondson (1981 apud HOUSE, 1997, p. 80), na gramática interativa de Edmondson e House (1981 apud HOUSE, 1997, p. 80) e nas categorias de análise dentro do projeto CCSARP (BLUM -KULKA, HOUSE e KASPER, 1989 apud HOUSE, 1997, p. 80)"1. A teórica (HOUSE, 1997, p. 83) menciona suas buscas às respostas para manifestações e causas de desentendimentos entre falantes de alemão e de língua inglesa e sugere que uma parte substancial desses desentendimentos culturais se deve às diferenças pragmáticas em determinadas áreas. Para a investigadora, um texto traduzido deveria trazer "fluência pragmática" para que a comunicação fosse bem-sucedida.

De acordo com a pesquisadora alemã (HOUSE, 1997), uma das questões que emergem de seu modelo original é a natureza do filtro cultural a ser aplicado na covert translation, ou, de acordo com Roscoe-Bessa (2010), "tradução velada" ${ }^{2}$, em que as diferenças em preferências comunicativas, mentalidades e valores são levados em consideração na tradução. Dessa maneira, parte do pressuposto de que a investigação sobre essas diferenças nas escolhas comunicativas socioculturalmente determinadas nas duas linguaculturas pode dar mais subsídios para a concepção desse filtro cultural. $\mathrm{O}$ objetivo da análise contrastiva de House (1997, p. 80) foi "estabelecer a presença ou ausência de diferenças comunicativas no com-

\footnotetext{
${ }^{1}$ Texto original: "on the discourse analysis model provided in Edmondson (1981) and in the interactional grammar of Edmondson and House (1981) as well as on the categories of analysis developed within the Cross-Cultural Speech Act Realization Project (CCSARP) (Blum-Kulka, House and Kasper 1989)" (Tradução nossa)

${ }^{2}$ Original: "Covert translation”. Tradução de Roscoe-Bessa (2010)
} 
portamento verbal de falantes nativos do inglês e do alemão" 3 . As características comunicativas do inglês delineadas pela autora serão recuperadas com vistas a uma nova comparação, entre o inglês e o português. De acordo com Krzeszowski (1990, p. 10), “a linguística contrastiva concentra-se em pares de línguas e explora semelhanças e diferenças entre elas" ${ }^{4}$. Salientamos, contudo, que não pretendermos realizar uma análise contrastiva propriamente dita.

Como constatamos que faltam pesquisas sobre esse mesmo tipo de diferenças entre as línguas inglesa e portuguesa, partimos das pesquisas conduzidas no Brasil acerca das características pragmático-discursivas do português. Entre as poucas observações que encontramos, estão:

- Segundo Negrão (2001), o português brasileiro é uma língua voltada para o discurso, ou seja, para o tópico. Para Huang (1982, 1984 apud NEGRÃO, 2001, p. 142): “dentre as propriedades caracterizadoras de uma língua voltada para o discurso está o fato de que o elemento proeminente em suas sentenças é o tópico ao passo que, nas línguas voltadas para a sentença, o elemento proeminente é o sujeito".

- De acordo com Le Berre (2008), o português brasileiro seria uma língua que daria preferência ao enunciado indireto. No português do Brasil, as formulações de ordens e pedidos explícitos são indiretivos. Para a autora, "Os pedidos indiretos são formas preferidas no português do Rio de Janeiro" (LE BERRE, 2008, p. 31). A autora comenta que o estrangeiro, desprovido de intuição linguística, que lhe permita perceber o tipo de ato social embutido em enunciado direto, pode reagir de forma socialmente inadequada. Ao utilizar um pré -pedido e uma justificativa, o falante marca a sua fala com

\footnotetext{
${ }^{3}$ Original: "...to establish the presence or absence of pragmatic differences in the verbal behaviour of English and German speakers." (Tradução nossa)

${ }^{4}$ Texto original: "Contrastive linguistics focuses on pairs of languages and explores similarities as well as differences between them." (Tradução nossa)
} 
um estilo de comunicação contextual. Le Berre (2008, p. 41) também cita Bennet (1998), para quem o pensamento contextual é típico das culturas latina, árabe, asiática e africana. Nesse tipo de comunicação o falante conduz a fala de forma circular, ou seja, ele não vai direto ao ponto. Ainda em Le Berre (2008), vemos que o uso do imperativo no português brasileiro tem implicações peculiares, como a impressão de um autoritarismo excessivo.

A fim de evitar esse tom, pode-se substituí-lo por estratégias mais polidas:

Como vimos em Meyer (1999), o brasileiro (ao menos da região sudeste e sul) evita o uso do imperativo, substituindo -o pelo presente do indicativo. As formulações de pedidos com o uso do tempo verbal imperativo são consideradas autoritárias, para os falantes dessa região do Brasil. Além de atenuar a imposição da ordem com o uso do tempo verbal presente do indicativo, o falante utiliza o diminutivo (um copinho) para minimizar o que está sendo solicitado. (LE BERRE, 2008, p. 63). [...] Este exemplo também evidencia que, no Brasil, muitas vezes, o universo do trabalho, ou seja, da rua, é englobado pelo universo da casa. De acordo com Meyer (2000), a patroa finge pedir aquilo que à empregada não é permitido negar. O brasileiro mascara as relações sociais da rua, neste caso, relações hierárquicas de trabalho, com relações pessoais, da casa. Com essa estratégia o locutor protege as faces dos interlocutores, dissimula a imposição da ordem e negocia o seu poder. [...] Pode-se observar que a polidez é mais do que uma estratégia para se manter boas relações. É um instrumento poderoso para a manutenção do poder, do locutor e de todos, para a não alteração do status quo. (LE BERRE, 2008, p. 71) 
Le Berre reporta-se também à frase ritualística situada por DaMatta (1997) "Sabe com quem está falando?", como maneira de dirigir-se ao outro, conhecida de todo brasileiro e que "implica sempre a separação radical e autoritária de duas posições reais ou teoricamente diferenciadas" (LE BERRE, 2008, p. 46).

Nosso próximo passo foram as comparações efetivadas por House (1997) entre o par linguístico alemão-inglês. Elas ocorreram a partir de análises em três diferentes níveis: nível superficial (no qual foram comparados tokens correspondentes nas duas língua culturas), nível mais profundo (no qual foram consideradas normas de expectativa ou recepção com respeito a certos atos ilocucionários e sua sequenciação) e, finalmente, em um nível ainda mais profundo, nos quais as funções sociais das categorias analíticas foram investigadas, assim como aspectos relativos aos níveis de formalidade, de polidez etc.

A partir disso, House (1997, p. 84) apresenta um quadro comparativo, no qual contrasta, de forma padronizada, cinco dimensões resultantes de sua análise de diferenças culturais entre as línguas alemã e inglesa. Propomos um cotejamento entre esses mesmos itens, tendo como referência as características identificadas por House na língua inglesa e suas especificidades. Pesquisamos equivalentes desses mesmos aspectos na língua portuguesa e, consoante as propostas de Le Berre (2009) e de Negrão (2001) e suas considerações, observamos padrões transculturais nessas cinco dimensões, constatando que em sua comparação com o português, na maioria das vezes, ocorrem semelhanças. A única diferença significativa refere-se à orientação discursiva de ambas as línguas, em que a língua inglesa, de acordo com o quadro de House (1997), tende ao discurso orientado para as pessoas (e não para o conteúdo) e, a língua portuguesa, segundo Negrão (2001) tende mais para o tópico do que para o sujeito.

A partir de constatações empíricas no que tange às características pragmático-discursivas do português brasileiro e por meio de 
uma análise mais minuciosa dos exemplos dados por House, a fim de encontrar o equivalentes pragmático-discursivas em português, seguem alguns exemplos práticos dessa comparação:

Conforme Negrão (2001) constatou em sua pesquisa, o português do Brasil tende mais para o tópico do que para o sujeito. Diferentemente de situações comunicativas em inglês, que mostram uma tendência pelo foco nas pessoas: "We apologize for any inconvenience work on our building site is causing you!" (HOUSE, 1997, p. 86), o português focaliza o tópico: "Estamos em reforma. Desculpe-nos o transtorno" (no Brasil). O exemplo inglês tem foco no interlocutor, enquanto que o foco do português é o tópico (a reforma).

Além disso, Luchtenberg (1994 apud HOUSE, 1997, p. 93) indica que nos manuais de computador em inglês em geral há uma "uma voz amiga para ajudá-lo", como no exemplo: "WordPerfect is backed by a customer support system designed to offer you fast, courteous service. If you've exhausted all other Help Avenues and need a Friendly Voice to help you with your problem, just follow these steps..." Esse exemplo enfatiza o interlocutor, enquanto em português o textoé muito mais impessoale direto. Em português, observemos o exemplo das instruções de instalação do programa Trusteer Rapport, disponível em https:// www.trusteer.com/pt-br/support/win-install-instructions: "O Rapport não suporta atualmente o Google Chrome em sua versão 43. O Rapport será automaticamente atualizado uma vez que o GC 43 seja suportado. Por hora, recomendamos utilizar outro navegador suportado para fins bancários. Clique aqui para visualizar uma lista completa das plataformas suportadas".

Relativamente à análise do início e fechamento de interações, House encontrou, no inglês, certos atos discursivos, como "de invasão de domínio", tais como pedidos de licença, na abertura das comunicações e explicações no momento da partida: (Excuse me, nas abordagens) e (I really must go now, no encerramento de diálogos), e não a despedida, pura e simplesmente. $\mathrm{O}$ momento de abertura de conversa, em português, no Brasil, em 
geral não é precedido do pedido de licença, mas se dá com um cumprimento, como Bom dia, ou Boa tarde. O fechamento do diálogo em português costuma ser mais direto do que o exemplo em inglês, com um simples Muito obrigado e, às vezes, o uso de algum termo de despedida. Esse fechamento de comunicações, no português do Brasil, geralmente é precedido por frases feitas como Então tá bom, muito utilizada. Emprega-se apenas a fórmula padrão de agradecimento, sem o uso de desculpas ou de justificativas.

No início ou término de diálogos - função fática da linguagem propriamente dita, observam-se no português as mesmas rotinas de frases "feitas" do inglês, como "Foi bom te ver", "A gente se fala", entre outras.

Com relação às tendências discursivas, de acordo com House (1997), falantes nativos do inglês tendem a selecionar estratégias orientadas de maneira interpessoal como, por exemplo, desarmar (I hate bothering you but), e um questionamento indireto, antes de um direto (Are you busy at the moment?), para efetivar um convite ou uma solicitação. Esses mesmos tipos de estratégias também são comuns nos falantes nativos do português. A fala (Desculpe incomodar...), bastante comum em abordagens, pode exemplificar a estratégia de "desarmar" em português. Outra situação comunicativa muito presente no português brasileiro é a pessoa perguntar o que o interlocutor fará em determinado momento antes de convidá -lo para fazer algo. Por exemplo, em geral, primeiro se questiona "O que você vai fazer sábado?" para depois fazer um convite ou uma solicitação para a mesma data. Isto significa que as estratégias discursivas se valem de rodeios, tanto numa quanto na outra língua. Em vez do emissor, enfatiza-se o interlocutor, fazendo o uso de medidas de apoio.

Em inglês se observa-se a orientação para as pessoas. House (1997) dá exemplo de um anúncio de café colombiano, que mostra um homem jovem saboreando o café com dizeres sobre o homem: "Look at the concentrated face of this coffee taster." Segundo Negrão (2001), o português tende mais para o tópico do que para o su- 
jeito, como bem demonstra um comercial brasileiro, com o café em primeiro plano e, no final, os dizeres: "nescafé - bons momentos".

Tanto no inglês quanto no português, ocorre o uso de marcadores discursivos para abrir, prorrogar, continuar uma conversação. Por exemplo, “well, you see, don't you?", e "assim, aí, então, né”.

Apresentamos, em seguida, outros exemplos de construções do inglês e do português que também devem ser levadas em consideração na tradução.

No inglês, apesar de o imperativo ser mais ameno do que no português, há também recursos para amenizar ordens ou pedidos. Nogueira (2013) analisou algumas diferenças culturais, duas das quais serão referidas neste estudo. A primeira situação são os aspectos culturais do uso de would, could e can com o efeito de polidez ao se pedirem favores. Em português podem ser colocadas em forma de pergunta direta, expressando a polidez pela entonação, podendo dispensar o uso de poderia, o que não é comum em inglês. Nesse contexto, "would" nem sempre precisa ter como equivalente em português o verbo no futuro do pretérito, embora também ocorram estruturas do tipo "Você me faria um favor?", ou com o emprego do imperfeito no lugar do futuro do pretérito, como em: "Você me quebrava um galho?"

Similarmente a esse caso, ainda de acordo com Nogueira (2013), existem palavras em inglês que, embora tenham sua tradução amplamente reconhecida, são utilizadas em situações um pouco diferentes, desafiando novamente o conceito de equivalência. Na Inglaterra é recorrente o uso de "please" no final de frases em que algo é solicitado, como em "Would you give me your work number, please?". No Brasil, ao pedir o telefone do trabalho de alguém e até mesmo ao pedir café numa lanchonete, pode-se dispensar o uso de por favor sem ser considerado rude. $\mathrm{O}$ efeito de polidez pode ser conseguido pela entonação, dispensando o uso de palavras específicas para isso, ou mesmo de alguns diminutivos, como já referido.

Questões linguísticas também têm implicações pragmáticas, como as diferenças entre os tempos verbais em inglês e português, mais notadamente no passado e nas if clauses, além do aspecto 
verbal. Entretanto, como geralmente são evidenciadas no ensino de língua estrangeira, não detivemos nossa análise nessas diferenças.

Outra dificuldade se dá na negação sentencial. Um exemplo é a tradução para o português de frases como "I don't think so.", que, em português, remete a frases com outra estrutura sintática, como "Eu acho que não." Outrossim, existe a possibilidade de duplas negativas em português, inversamente ao inglês. A frase "We don't do anything" não se traduz por (Nós não fazemos algo), mas pelo uso de duas palavras negativas na mesma frase: "Nós não fazemos nada", entre outras situações, que podem apresentar obstáculos durante $o$ ato tradutório.

Também problemática é a tradução da adjetivação em inglês, em que a anteposição do adjetivo ao substantivo possibilita, sem prejuízo da coesão, a enumeração de diversos adjetivos para um único substantivo. Isso é inviável em português. Para ilustrar, observe-se o seguinte excerto de um texto de Mona Baker (2010, p. 115): "what we need is a framework that recognizes the varied, shifting and ongoingly negotiable positioning of individual translators in relation to their texts, authors, societies and dominant ideologies", traduzido por nós com ajustes como: "O que precisamos é de uma abordagem que reconheça o posicionamento variável e continuamente negociável do tradutor em relação à ideologia implícita nos textos, autores, sociedades e eventos de interpretação." Em português houve a fusão de "shifting" e "varied", traduzidos por "variável” e, adiante, a supressão de "individual”, colocando "tradutor" no singular. A língua portuguesa, cuja ordem direta é substantivo mais adjetivo, oferece como possibilidade para a tradução de diversos adjetivos para um único substantivo em inglês, além da fusão e da supressão citadas, o desenvolvimento de orações ou o emprego de locuções adjetivas.

Em meio às diferenças comunicativas entre o português e o inglês pode-se situar, ainda, o uso dos pronomes de tratamento você, vocês, das palavras senhor, senhora, senhores e senhoras, e da palavra "dear". Piccolo (2002, p. 1) ressalta que: 
O português, como outras línguas também neolatinas, possui diversos pronomes de tratamento específicos para se referir ao interlocutor de maneira cerimoniosa, reverente, formal e informal. No entanto, duas exclusivas palavras exercem verdadeiro papel de pronome pessoal no discurso cotidiano da língua: o substantivo senhor e o pronome de tratamento você.

Em inglês, somente pronome pessoais são empregados para se referir ao destinatário ( $2^{\mathrm{a}}$ pessoa), embora haja alguns usos avançados e curiosos de "you”, conforme explicita Fred (do sítio Inglês no supermercado):

Pode-se usar o pronome you antes de substantivo quando se quer ofender alguém enfaticamente: You idiot! (Seu idiota!); You fool! (Seu tolo). O sítio reporta a fonte: The Free Dictionary. Em português, obtém-se o mesmo efeito empregando, como a própria tradução do sítio demonstra, o pronome de tratamento "seu", "sua". Ressalte-se, entretanto, que o emprego de "sua" nesta categoria de pronome de tratamento ocorre no português do Brasil somente neste sentido de ofensa ("Sua Burra!"; "Sua Vadia!". Exemplos nossos).

O emprego de "senhor" e "senhora" não apresenta diferenças significativas no português e no inglês, a não ser que em português geralmente precedem o primeiro nome e em inglês o sobrenome. Além disso, em inglês, tanto a palavra "Sir" quanto a palavra "Mr." significam "Senhor". No entanto, emprega-se "Mr." quando o nome da pessoa vem expresso: $M r$. Munday, por exemplo; e "Sir" somente se o nome da pessoa a que se refere não tiver sido explicitado: Yes, Sir. Em português, Piccolo (2002, p. 4) assinala que: 
Também se observa o emprego sarcástico ou irônico da forma senhor para fazer notar ao interlocutor atenção, pretensão, soberba ou mesmo falta de modéstia, normalmente para se dirigir a um falante mais novo (quebra da regra), como em: $O$ senhor vai sair agora e vai voltar quando? (pai perguntando ao filho)

O Dicionário Oxford reporta o uso de "Dear Sir/Madam" no início de cartas comerciais ou formais. Em português, nessa situação, não se emprega "Querido(a) Senhor/Senhora". Ademais, a palavra "dear" e sua tradução em português "querido (a)" têm uso comunicativo muito diferente no português e no inglês. Diferentemente do português, de acordo com Gonzáles (2013 apud REZENDE, 2013) $)^{5}$, em inglês ela não é tão comumente utilizada, e que é especialmente raro um homem chamar alguém de "dear", como se utiliza com frequência no português brasileiro, em que é comum ao homem chamar uma mulher de "querida", nas relações familiares ou próximas. Gonzáles (2013 apud REZENDE, 2013) destaca o uso de "dear" em correspondências formais: Dear Mr. Smith; Dear Sir; Dear Hiiring Comittee, o que não ocorre em português com "Querido (a)". Há, ainda, a interjeição "Oh, dear”, que geralmente expressa preocupação ou desânimo, ou mesmo sarcasmo, sem equivalente em português.

Dessa maneira, tomando como base as descrições de House (1997), concluímos que há mais semelhanças do que diferenças pragmáticas entre o par linguístico inglês-português. Entretanto, algumas diferenças culturais podem ser identificadas ao se problematizarem algumas questões da língua inglesa com vistas à sua tradução para o português, como visto nos exemplos expostos. Este foi um levantamento preliminar. Acreditamos serem ainda necessárias pesquisas das especificidades pragmáticas do par linguístico inglês-português.

5 Texto de partida escrito em inglês disponível em http://livemocha.com/ blog/2013/02/13/dear-english-learners-here-are-5-things-you-should-knowabout-the-word-dear/. Tradução de Rezende (2013). 


\section{Referências}

BAKER, Mona. Reframing conflict in translation. In: BAKER, Mona (Ed.). Critical readings in translation studies. New York \& London: Routledge, 2010, p. 113-129.

FRED. Usos avançados e curiosos de "You". Publicado em 20 novembro de 2013. Disponível em http://www.inglesnosupermercado.com.br/usos-avancados-e-curiosos-dos-pronomes-i-you-he-she-it-we-they/. Acesso em 13 jun. 2015.

HOUSE, Juliane. Translation quality assessment: a model revisited. Tübingen: Narr, 1997, $93 \mathrm{p}$.

IBM..COM.. Instruções para instalação nos sistemas operacionais Windows. Disponível em https://www.trusteer.com/pt-br/support/win-install-instructions. Acessos em: 15 jun. 2015 e 5 set. 2015.

KRZESZOWSKI Tomasz P. Contrasting Languages: The Scope of Contrastive Linguistics. Berlin: Mouton de Gruyter, 1990.

LE BERRE, Carla Chiappetta. Formulação de atos diretivos, em língua oral, no português do Brasil. Dissertação (Mestrado em Letras): Rio de Janeiro: Pontifícia Universidade Católica do Rio de Janeiro, 2008. p. 71-72 Disponível em: http:// www.maxwell.vrac.puc-rio.br/11177/11177_4.PDF Acessos em: 31 mai. 2015 e 23 ago. 2015.

NEGRÃO, Esmeralda Vailati. O princípio de projeção estendida no português brasileiro. Revista Letras, n.56, Curitiba, jul/dez 2001. p. 141-155.

NOGUEIRA, Alessandra Sartori. Diferenças culturais percebidas por brasileiros no uso da língua inglesa no exterior e seu tratamento em livros didáticos. Belo Horizonte: Revista brasileira de linguística aplicada, vol.13, $\mathrm{n}^{\circ} .1$, Jan./Mar. 2013, p. 345-368. Disponível em http://www.scielo.br/pdf/rbla/v13n1/aop1612. pdf. Acesso em 13 jun. 2015. 
PICCOLO, Alexandre Prudente. (19) A alternância entre os pronomes "você" e "senhor" (2002). Disponível em: http://www.unicamp.br/iel/site/alunos/publicacoes/textos/a00005.htm. Acesso em 13 jun. 2015. p. 1-5.

REZENDE, Márcio. Caros estudantes de inglês: Aqui estão 5 coisas que você deve saber sobre a palavra "dear". The conversation, a blog from livemocha. 14 fev. 2013. Disponível em http://livemocha.com/blog/2013/02/14/caros-estudantes-de-ingles-aqui-estao-5-coisas-que-voce-deve-saber-sobre-a-palavra-dear/?lang =pt-br. Acesso em 15 jun. 2015.

ROSCOE-BESSA, Cristiane. A tradução-substituição. Brasília: Editora Centro, 2010. $107 \mathrm{p}$.

Recebido em: 08/11/2015

Aceito em: 04/02/2016 Publicado em maio de 2016 